\title{
SNOW-CREEP PRESSURE ON MASTS
}

\author{
by
}

Jan Otto Larsen, Jens Laugesen, and Krister Kristensen

(Norwegian Geotechnical Institute, P.B. 40, Taasen, 0801 Oslo 8, Norway)

\section{ABSTRACT}

Snow-pressure measurements have been carried out on two masts at the NGI avalanche station in Grasdalen, western Norway. These two tubular masts have diameters of 0.22 and $0.42 \mathrm{~m}$, respectively, and are situated on a $25^{\circ}$ slope with a deep snow cover.

The most important conclusions are that within a homogeneous snow-pack there is a close correlation between snow-creep pressure and the product of acceleration due to gravity, $g$, density, $\rho$, and snow depth, $H$, that the highest pressures are recorded in late winter when the snow-pack is at the $0^{\circ} \mathrm{C}$ isothermal, and finally that a weak $0^{\circ} \mathrm{C}$ isothermal snow layer at ground level appears to increase snow pressure.

\section{INTRODUCTION}

Pressure from snow creep is important in the design of structures such as ski-lifts and power-line masts, which of ten have to be constructed on steep hillsides with deep snow cover. This is a problem which has been described by Bader and others (1939). Brown and Evans (1975) have

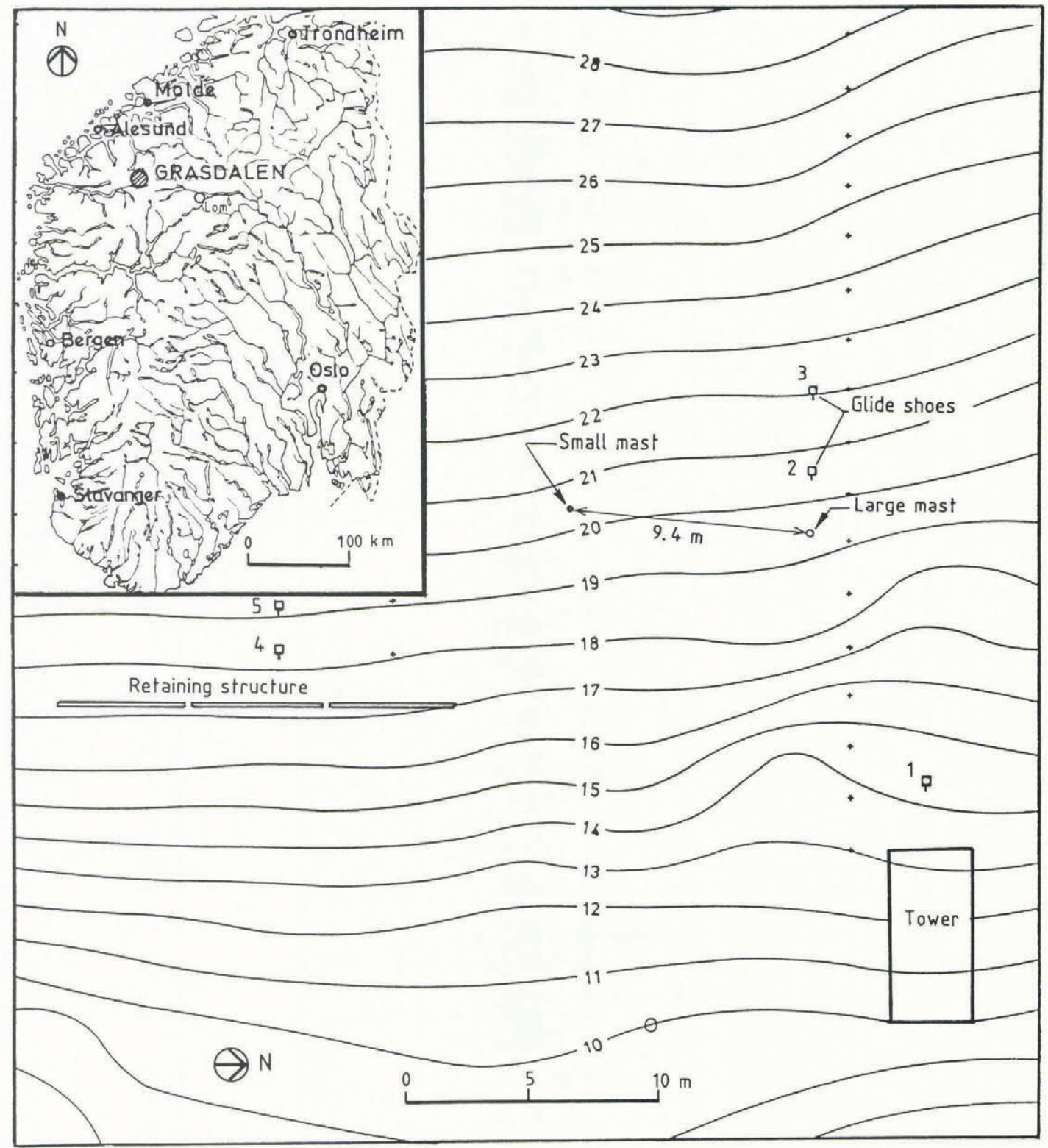

Fig. 1. The research field in Grasdalen, western Norway. 
developed a calculation procedure for stress and deformation analysis of a snow mass undergoing creep and gliding, whilst Mathews and Mackay (1975) have made field measurements for small-diameter poles. Few fieldmeasurement results have been published; there are, however, several publications dealing with snow-creep pressure in relation to retaining structures. In this paper we present the results of field observations on two masts, with diameters of 0.22 and $0.42 \mathrm{~m}$, respectively. The snow-creep pressures are recorded as maximum moments on the masts, and are related to the most important characteristics of snow.

\section{DESCRIPTION OF THE MEASUREMENTS TAKEN}

The test site lies close to the NGI research station in Grasdalen, western Norway (Fig. 1), at an elevation of $1100 \mathrm{~m}$. In such a maritime climate, snow depth normally fluctuates between 2.0 and $4.5 \mathrm{~m}$. The surface of the $25^{\circ}$ slope at the site is partly rocky and partly moss-covered, a rocky surface is present above the large mast, and an incomplete coverage of moss is found up-slope of the small mast. NGI also has a $15 \mathrm{~m}$ long snowretaining structure at the site. Data recordings from this retaining structure have previously been presented by McClung and others (1984), and by Larsen and others (1985).

The glide of the snow cover up-slope from the large mast was estimated by measuring its displacement with glide shoes; readings taken periodically showed that negligible glide occurred. The depth of snow above the masts was measured every fortnight. Snow properties, including density, temperature, ram-penetrometer resistance, snow-crystal type, and moisture content, were measured at the site at least at monthly intervals. The frequency of measurement was increased towards the end of the winter. In the analysis of the influence of snow creep on the structures, we have made use of averaged values of both snow depth and snow density on the up-slope side of the masts.

The two masts are equipped with Geonor P-200 strain gauges mounted in pairs (Figs 2 and 3 ). The large mast, $6 \mathrm{~m}$ high and $0.42 \mathrm{~m}$ in diameter, has a high stiffness given by the section modulus, $W=575 \mathrm{~cm}^{3}$, and was erected perpendicular to the ground surface in 1975. The small mast, $4.5 \mathrm{~m}$ high and $0.22 \mathrm{~m}$ in diameter, is more flexible, with $W=294 \mathrm{~cm}^{3}$, and was erected $9.4 \mathrm{~m}$ south of the large mast in 1983 (Fig. 1). This instrumentation has enabled us

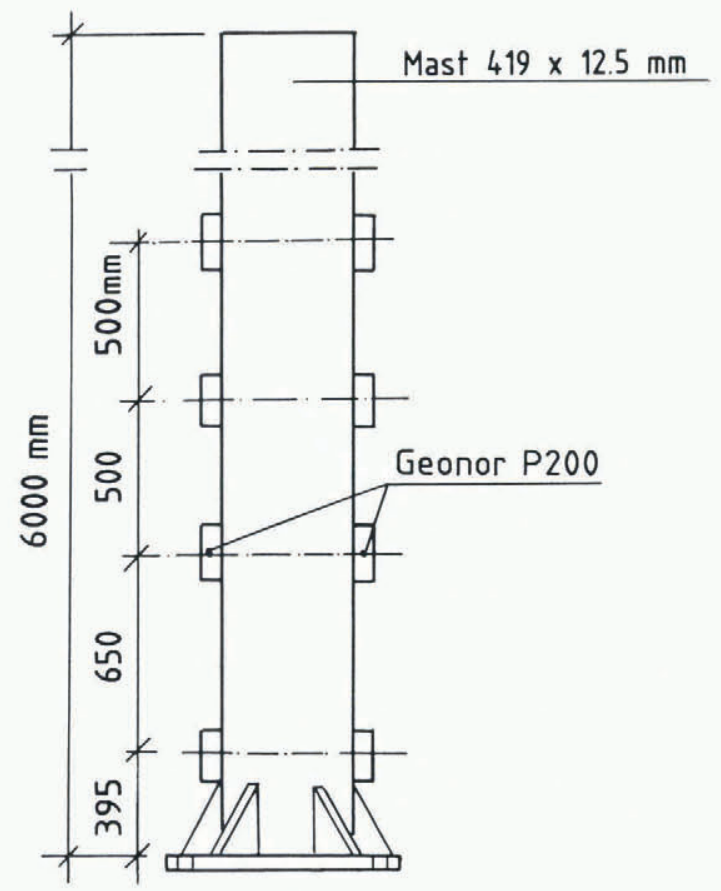

Fig. 2. Instrumentation of the large mast.

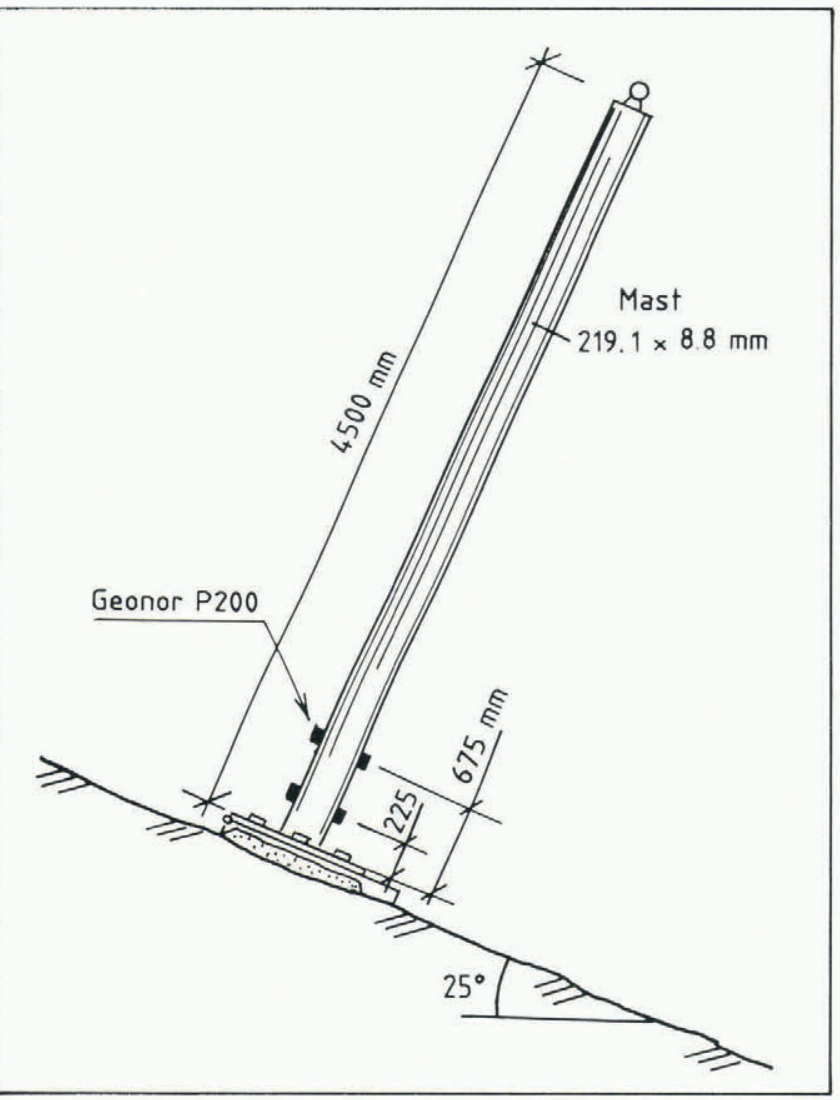

Fig. 3. Instrumentation of the small mast.

to calculate moments and shear forces at different cross-sectional positions on the masts. From the moment values obtained we are able to make estimates of the moment and snow-pressure distributions throughout winter seasons. For the large mast, measurements have been made
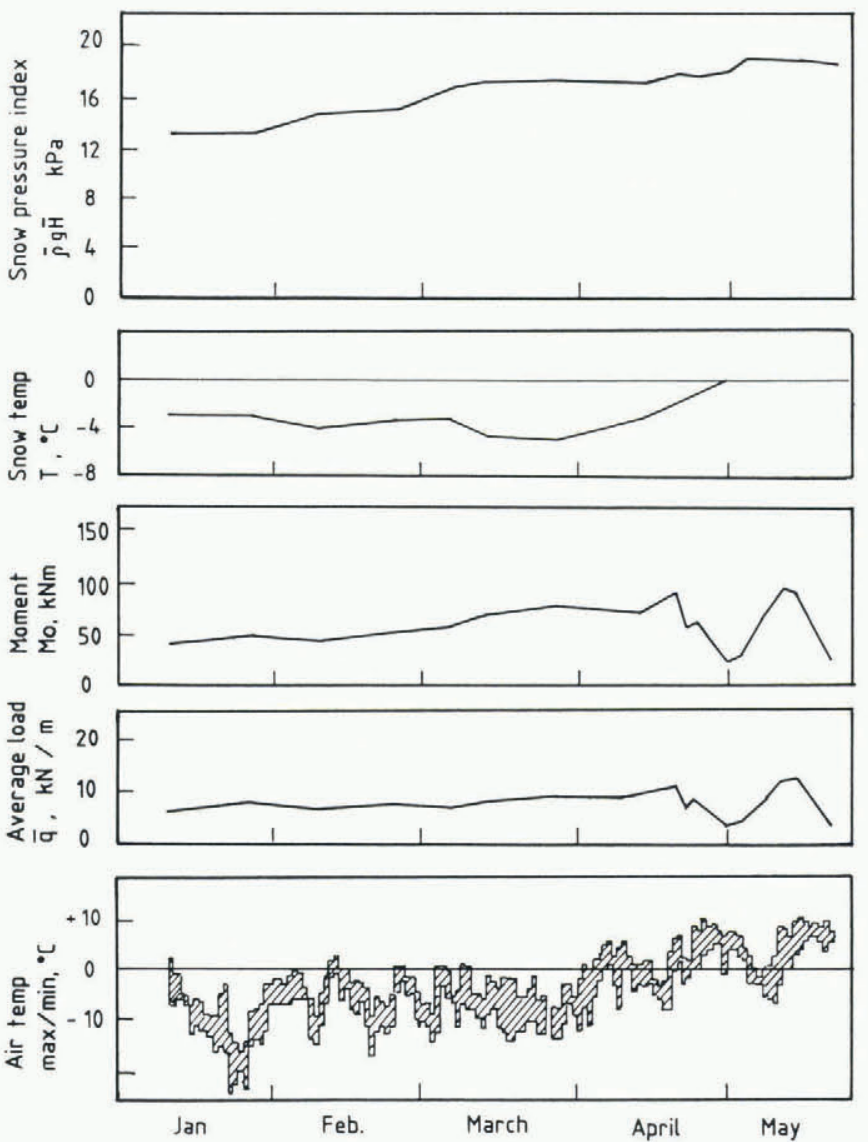

Fig. 4. Variation of snow loads on the large mast with snow-pack parameters, 1984. 


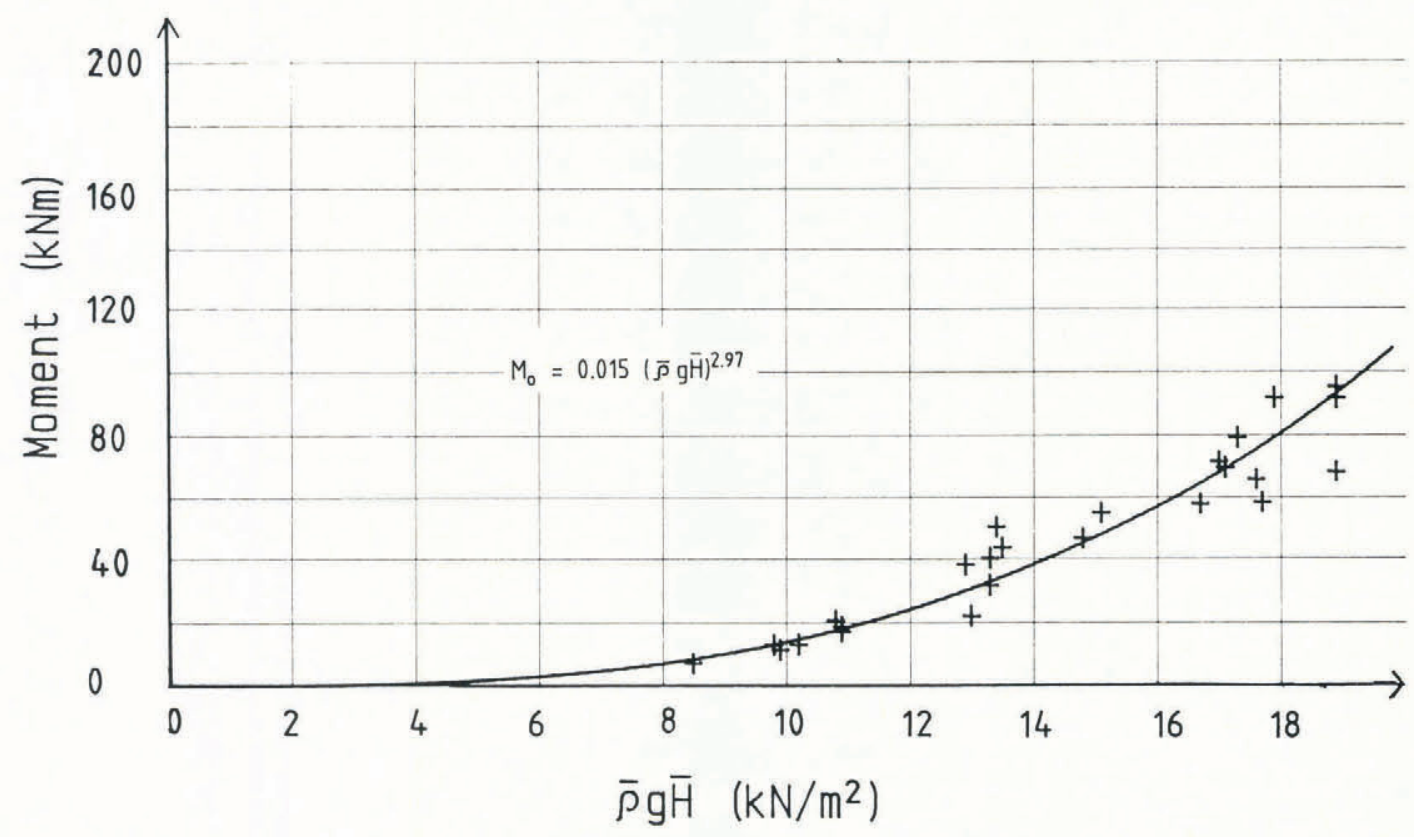

Fig. 5. Maximum moments in the large mast (period 1984-87) as a function of the "snow-pressure index" $\bar{\rho} g \bar{H}$.

over a period of 12 years. Because of the low accuracy of measurements when the snow depth is less than $3 \mathrm{~m}$, however, we have only 6 seasons with useful data. After erecting a small flexible mast in 1983 we have been able to study scale effects due to the diameter of the mast, and also to obtain useful measurements when the snow depth varied between 2 and $3 \mathrm{~m}$. In the period 1983-87, three of the winters had sufficient snow for us to obtain useful measurements.

\section{INTERPRETATION OF RESULTS}

In Figure 4 we have defined $\rho g H$ as the snow-pressure index, if $\rho$ is average density of the snow-pack, $g$ is acceleration due to gravity, $H$ is average snow depth upslope from the mast.

Snow temperature is the temperature at the vertical mid-point of the snow cover; moment, Mo, is the estimated maximum moment in the mast; air temperature is measured at the NGI research station which is $200 \mathrm{~m}$ below the field site. Figure 4 shows the steady increase in the moment in the large mast during a season with cold snow $\left(T<0^{\circ} \mathrm{C}\right)$, which is caused by increasing snow depth and increasing snow density. That is to say, such conditions increase the magnitude of the snow-pressure index. The estimated average load, the pressure, shows a similar increase.

A correlation between moment and the snow-pressure index for the period with cold snow is shown in Figure 5, where data from the period 1984-87 are presented. The best-fit curve for the data obtained for the big mast is found by regression analysis, such that

$$
\text { Mo }=0.015(\rho g H)^{2.97} \quad \text { with } r^{2}=0.94 \text {. }
$$

A similar relationship for the small mast is presented in Figure 6 with the best-fit curve

$$
\text { Mo }=0.015(\rho g H)^{3.14} \quad \text { with } r^{2}=0.95 \text {. }
$$

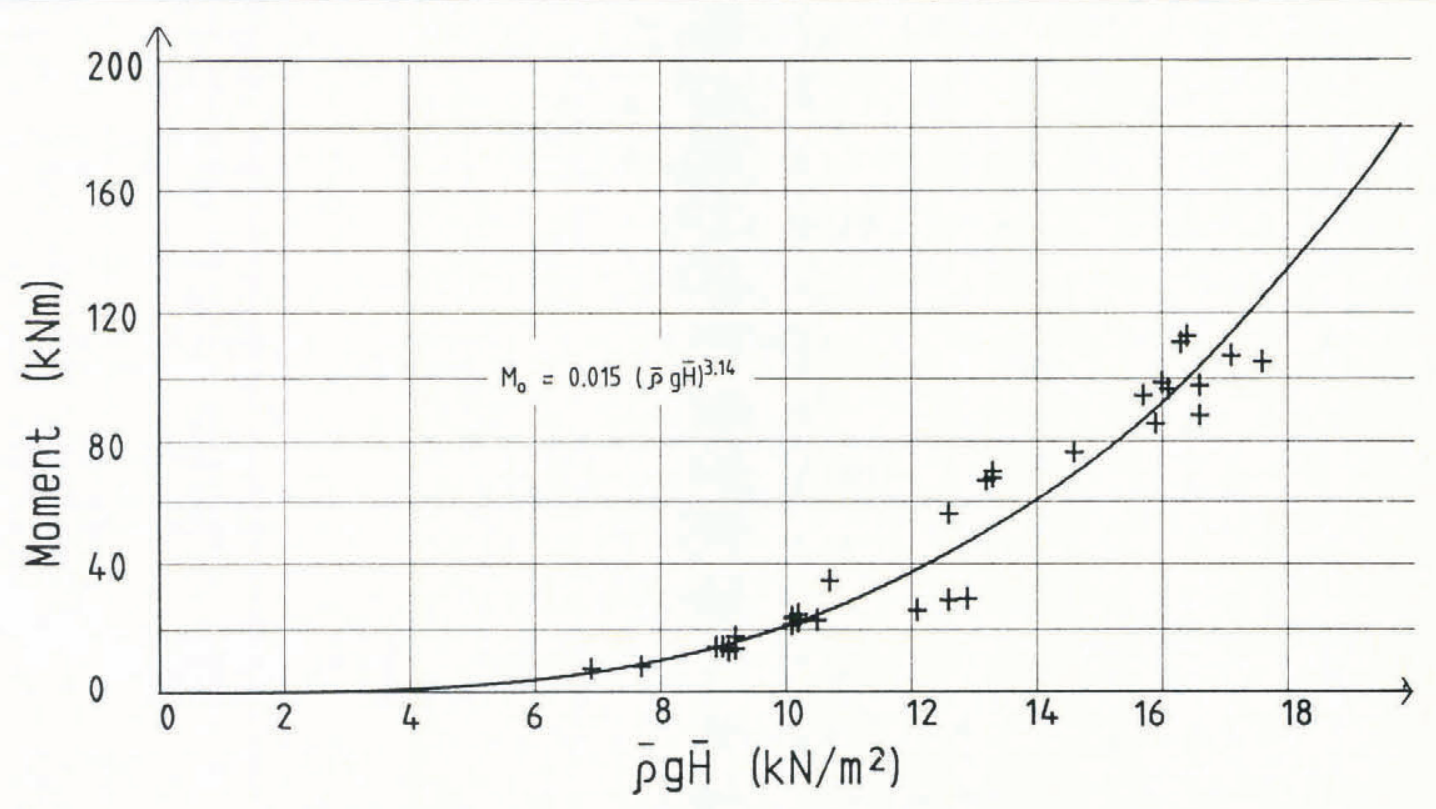

Fig. 6. Maximum moments in the small mast (period 1984-87) as a function of the "snow-pressure index" $\bar{\rho} g \bar{H}$. 

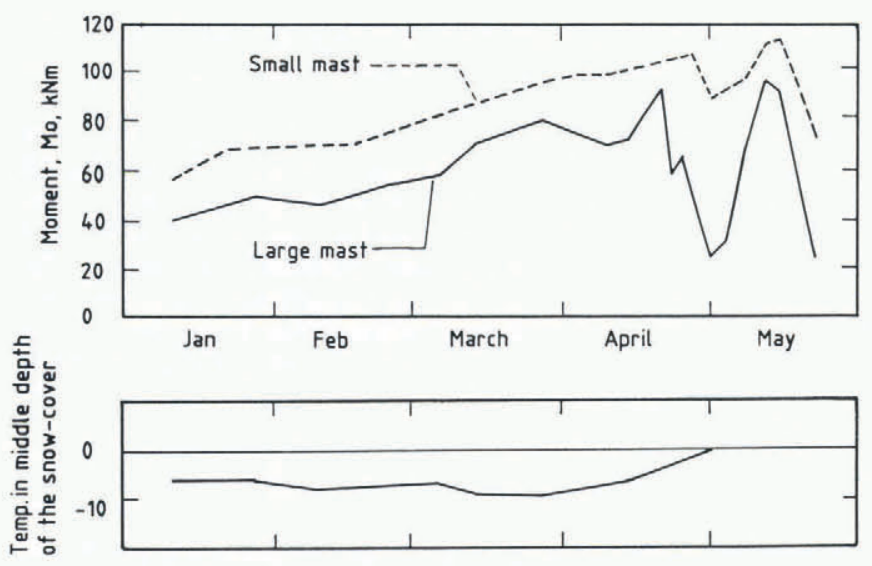

Fig. 7. The variation of maximum moments in the masts compared with the temperature in the middle depth of the snow cover during the winter, 1984.

In late winter, as snow cover attains a $0^{\circ} \mathrm{C}$ isothermal, there is a considerable drop in moment due to melting of the snow around the masts (Fig. 4). This melting is caused mainly by the heating of the masts as they are exposed to increasing air temperatures. Craters appear around the masts, caused by wind in the cold season and by melting during late winter; the large mast is influenced much more by these effects than the small mast. When cold air temperatures occur within the melting period, the highest moment values of the winter are recorded, these high values being obtained because the snow once again freezes within the upper layers of the snow cover. Fresh falls of snow can also contribute to an increase in moment; as can be seen in Figure 4, such an increase in moment took place in mid-May 1984.

Figure 7 shows the typical pattern of variation in maximum moment, Mo, on the masts with time. From the measurements obtained, it is clear that the small mast is exposed to larger moments than the large mast at all stages of the season. The crater effect cannot be the only reason for this, and we believe the full explanation also involves boundary effects around the mast and on the ground. The up-slope ground surfaces at the sites of the structures are not identical because there is partial moss cover above the small mast and bare rock only above the large mast. No measurement of glide was made on the rocky surface, and we have no reference standard for the snow cover on the partially moss-covered surface. The highest moments recorded were measured during the 1981 winter period, and despite there being no measurable glide data in our observations, the estimated moments were between two and three times higher than for other seasons with a similar snow-pressure index (Fig. 8). The 1981 winter was unusually warm, with temperatures in the bottom layer around $0{ }^{\circ} \mathrm{C}$ isothermal throughout most of the season (Fig. 9). We assume that the high pressures recorded can be explained by a high viscous-creep rate in the weak bottom layer. The values of the moment for each $0.5 \mathrm{~m}$ length along the large mast enable us to make rough estimates of the pressure distribution. There is a clear tendency for increases in pressure to occur against the lower part of the mast. Unfortunately, limits on the accuracy of the measurements available do not allow a more exact analysis to be made.

\section{CONCLUSION}

Snow-creep measurements carried out on two masts of different diameters on the same slope have yielded some useful information. The most important results are listed below:

There is a good correlation between the moment on a mast and the value of the snow-pressure index, $\rho g H$, if snow cover is homogeneous and cold $\left(T<0^{\circ} \mathrm{C}\right)$.

The largest moment value is obtained in late winter, when the snow-pressure index has its maximum value and the snow-pack is subjected to a $0^{\circ} \mathrm{C}$ isothermal.

Heating of the mast in periods when air temperature rises above $0^{\circ} \mathrm{C}$ causes melt craters to appear in the snow cover around the masts, and this decreases the size of the moments.

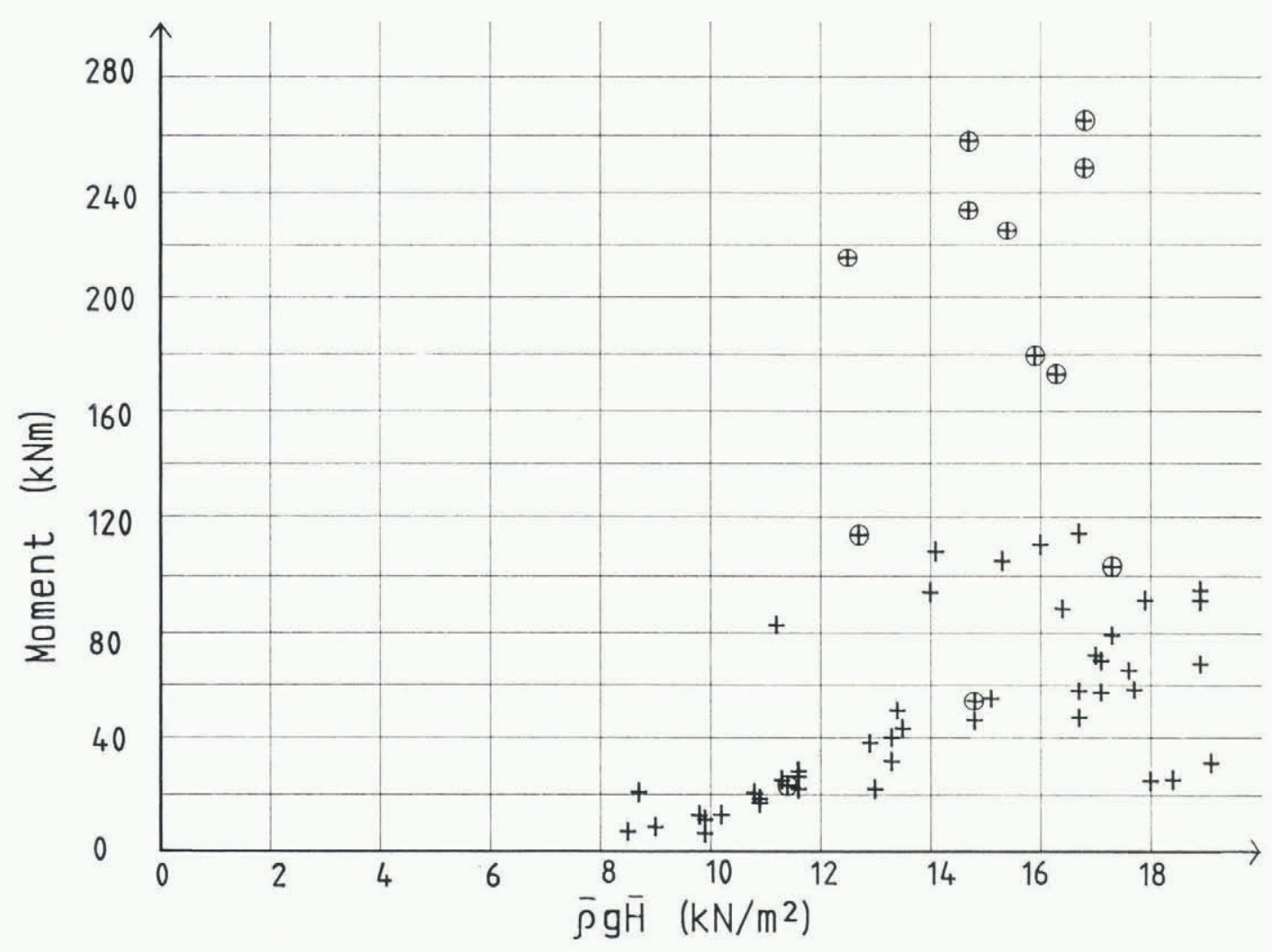

Fig. 8. Maximum moments in the large mast (period 1975-87) as a function of the "snow-pressure index" $\bar{\rho} g \bar{H}(\oplus$ 1981). 


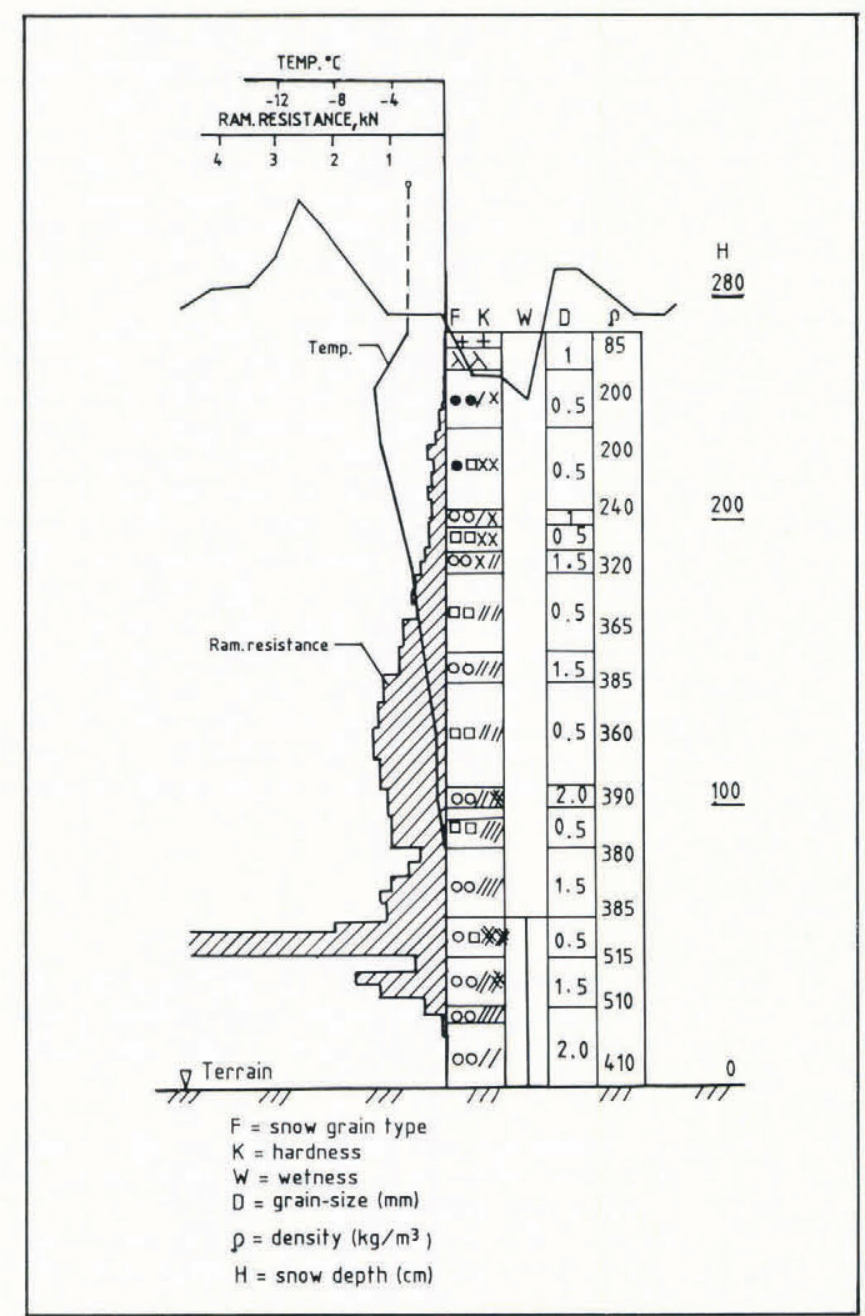

Fig. 9. A typical snow profile for the winter 1981 (21 February).
A weak $0{ }^{\circ} \mathrm{C}$ isothermal bottom layer in the snow cover appears to increase the pressure exerted by the snow.

There is large scatter in the data gathered for this work, but the results are considered potentially useful both for the design of mast structures likely to be subjected to deep snow cover and as the basis for the development of a theoretical model of snow-creep pressure on masts. The field investigations need to be continued, and we are optimistic that more data concerning glide and creep effects on the masts will improve our understanding of these effects.

\section{ACKNOWLEDGEMENTS}

The authors wish to thank the Norwegian State Power Board and the National Fund for Natural Disaster Assistance for their co-operation and sponsorship. Many thanks also go to NGI and to our colleagues in the avalanche section for their contributions to our discussions and data analysis.

\section{REFERENCES}

Bader, H., and 6 others. 1939. Der Schnee und seine Metamorphose. Beitr. Geol. Schweiz, Geotech. Ser. Hydrol., 3. [English translation: SIPRE Translation 14, 1954.]

Brown, C.B. and R.J. Evans. 1975. Effect of glide and creep on rigid obstacles. International Association of Hydrological Sciences Publication 114 (Symposium at Grindelwald 1974 - Snow Mechanics), 407-414.

Larsen, J.O., D.M. McClung, and S.B. Hansen. 1985. The temporal and spatial variation of snow pressure on structures. Can. Geotech. J., 22(2), 166-171.

McClung, D.M., J.O. Larsen, and S.B. Hansen. 1984. Comparison of snow pressure measurements and theoretical predictions. Can. Geotech. J., 21(2), 250-258.

Mathews, W.H. and J.R. Mackay. 1975. Snow creep: its engineering problems and some techniques and results of its investigation. Can. Geotech. J., 12(2), 187-198. 